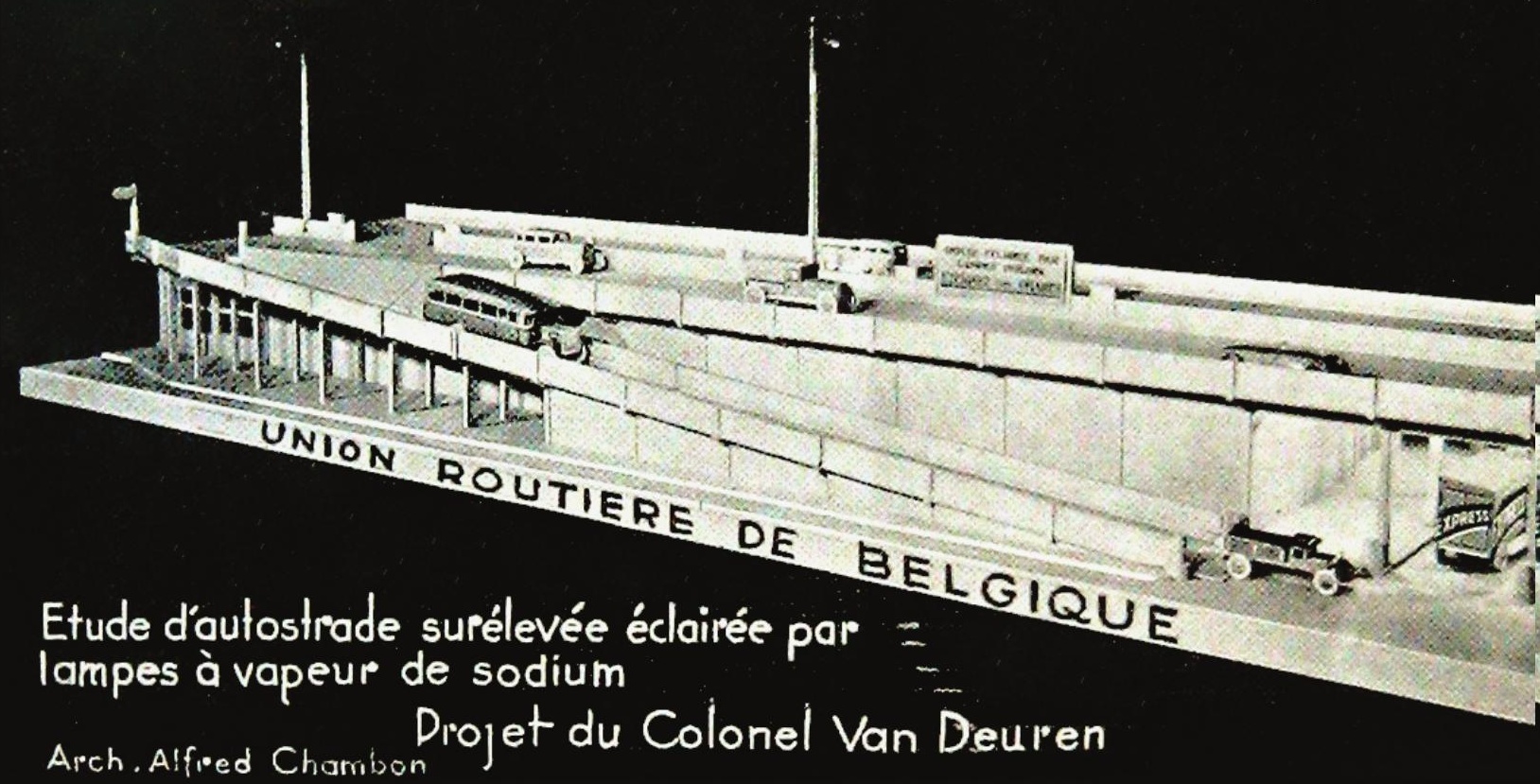




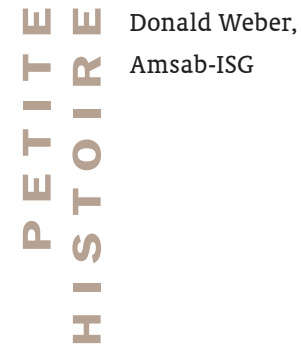

\section{Autostrades in de lucht... en dwars door Gent}

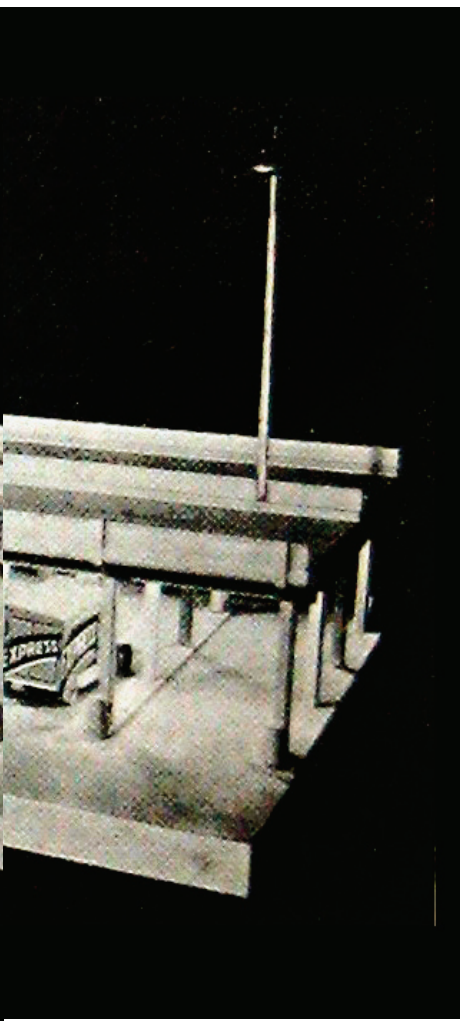

Brussel, Academiepaleis, 20 oktober 1934. Voor een uitgelezen publiek van vooraanstaande ambtenaren en politici, op uitnodiging van de automobilistenorganisatie Union Routière de Belgique, presenteert kolonel Van Deuren een ambitieus plan om in België een netwerk te bouwen van "autostrades suspendues". Het gaat om niet minder dan $850 \mathrm{~km}$ nieuwe wegen, die alle grote steden van het land met elkaar verbinden. Het plan-Van Deuren voorziet autowegen van achttien meter breed over zes rijvakken, drie in elke richting, gebouwd als viaducten, vijf meter boven de grond. Zo kunnen hindernissen onderweg gemakkelijk vermeden worden en de uitgestrekte terreinen onder de autostrades gebruikt voor openbare nutsvoorzieningen, hospitalen, kantoren, woongelegenheden enz. Prof. ing. Pierre Van Deuren, die zelf belangen heeft in de betonindustrie, stelt dat voor de realisering veertigduizend arbeiders nodig zijn gedurende tien jaar. Nadat de automobielpers over het plan bericht heeft, brengt ook Le Soir Illustré in juni 1934 een reportage. Hoewel het project-Van Deuren grondig afwijkt van de plannen van Bruggen en Wegen, zal het de blauwdruk worden van het latere Belgische autowegennet. ${ }^{1}$

Eerder dat jaar had een ander wegenplan reeds de pers gehaald: de Gentse ingenieur Van den Hoeck stelt eind 1933 voor om boven de bestaande spoorwegen een verdieping te bouwen op grote zuilen, voorbehouden voor het autoverkeer. De bestaande stations in de steden zouden dan kunnen uitgebreid worden met een autogarage, een benzinestation enz. ${ }^{2}$

Autostrades in de lucht. Het ontwerp van kolonel Van Deuren uit 1934 voorzag een nationaal netwerk van autostrades op viaducten (uit: L'Automobile belge, 20/02/1934, p. 54). 


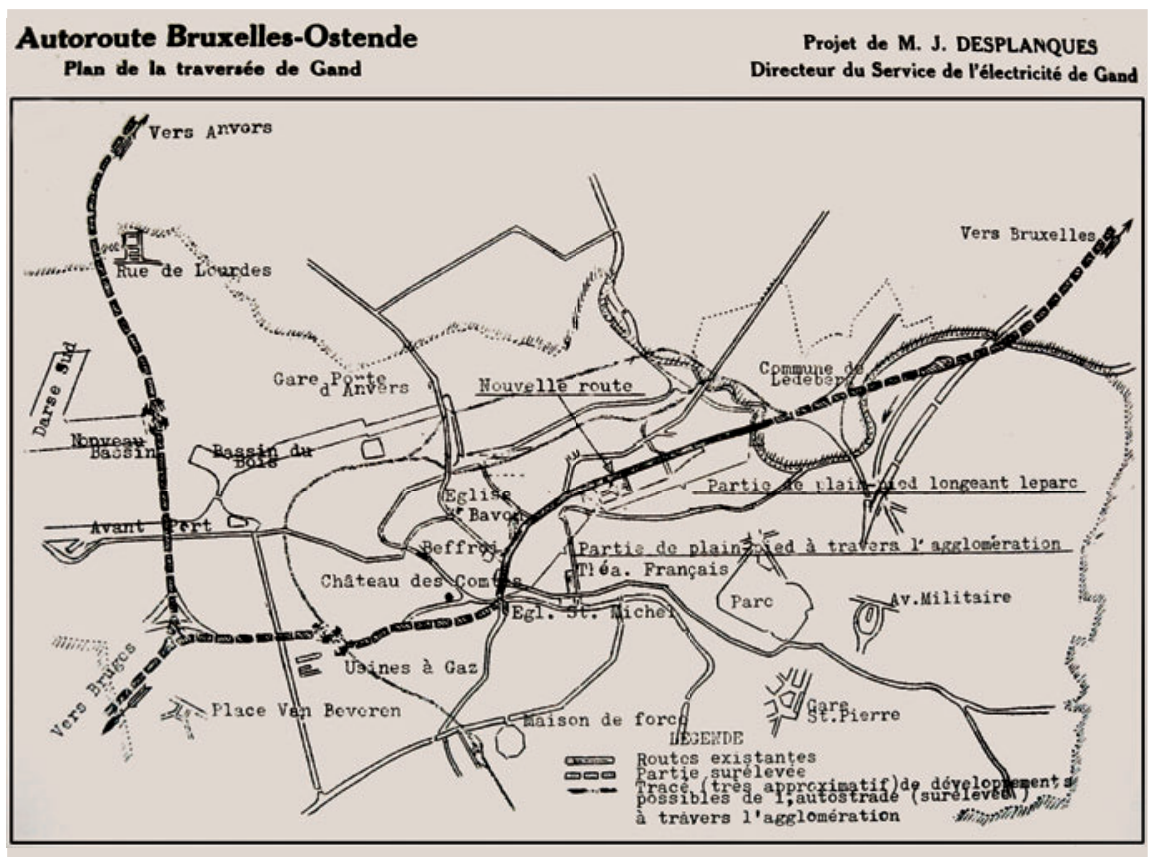

Plan-Desplanques uit 1935: doortocht van de autoweg Brussel-Oostende door het centrum van Gent (uit: Mon Auto, oktober-november 1935, p. 219).

In mei 1935 richt Edward Anseele, zelf ex-minister van Openbare Werken, zich in de Kamer tot zijn partijgenoot, de toenmalige minister van Openbare Werken, Hendrik de Man. Deze heeft, zoals aangekondigd in zijn Plan van de Arbeid, even tevoren de beslissing genomen om in België autostrades aan te leggen. Anseele is tevreden dat er een autoweg Brussel-Oostende is voorzien, maar hij is er minder over te spreken dat deze weg onder Gent langs Zwijnaarde zou passeren. Hij pleit ervoor om de autoweg door het centrum van Gent te laten lopen, eerst door het Zuidpark ("donc sans aucune gêne"), dan via de Vlaanderenstraat rakelings langs de Sint-Baafskathedraal en het belfort, om via de Sint-Michielsbrug de stad te verlaten. Op deze wijze zouden de automobilisten een uitmuntend zicht hebben op de Gentse historische torenrij, hetgeen volgens Anseele de toeristische aantrekkingskracht van de stad ten zeerste ten goede zou komen. Er zijn zes opritten voorzien, onder meer in de De Pintelaan en op de Sint-Michielsbrug. De autostrade zou veertien meter breed worden en in het midden over de hele lengte een afsluiting krijgen in de vorm van een $75 \mathrm{~cm}$ hoge muur, om botsingen te vermijden. ${ }^{3}$

Hoewel het duidelijk is dat de minister en zijn administratie voor dergelijke plannen weinig voelen, geeft men het in Gent niet zo gauw op. In het najaar van 1935 pakt het hoofd van de elektriciteitsdienst van de Stad Gent, ingenieur Desplanques, uit met een volledig uitgewerkt plan. In het plan-Desplanques gebeurt 


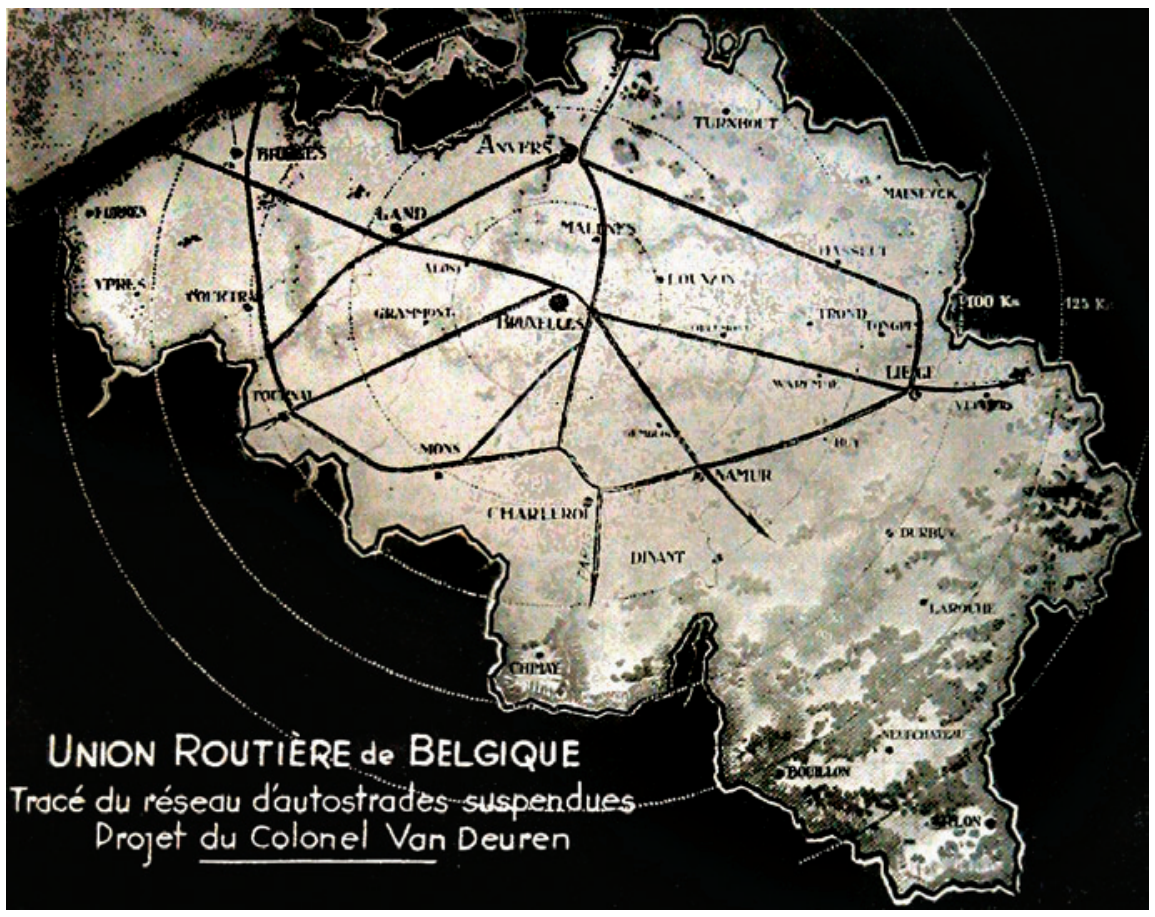

Het schema van autostrades van Van Deuren uit 1934 lijkt verrassend sterk op het huidige netwerk (uit: L'Automobile belge, 20/02/1934, p. 53).

de doortocht van de autostrade door Gent grotendeels in de vorm van een viaduct, maar het eigenlijke centrumgedeelte, langs de kathedraal en het belfort, verloopt langs de begane grond. Ingenieur Desplanques volhardt, zoekt en krijgt de steun van de invloedrijke Gentse professor en internationale betonexpert Gustaaf Magnel. Een aangepaste versie van zijn plan, nu het plan-Desplanques-Magnel geheten, wordt verdedigd op het vierde Belgische Wegencongres, dat in 1938 in Gent wordt gehouden. ${ }^{4}$ Een autostrade aan de voet van het belfort zou er nooit komen, maar vandaag brengt de B401, de autostrade langs het Zuidpark, de automobilist wel degelijk tot vlak bij het historische hart van de stad.

(1) L'Automobile belge, 20/02/1934, p. 5354; La Route belge, maart 1934, p. 9; Mon Auto, maart 1934, p. 65-66; Le Soir Illustré, 02/06/1934, p. 6. Zie ook L'Automobile belge, 10/02/1925, p. 1-7.

(2) L'Automobile belge, 05/01/1934, p. 3-4.

(3) Parlementaire Handelingen. Kamer van Volksvertegenwoordigers, 23/05/1935, p. 1182-1183.
(4) Mon Auto, oktober-november 1935, p. 218219; Bâtir, januari 1937, p. 1007-1010; J. DESPLANQUES, Organisation du réseau routier en vue de réaliser le rendement maximum des divers modes de locomotion, en tenant compte des incidences diverses dans les autres domaines de l'économie nationale, SintAmandsberg: Van Doosselaere, 1938, 44 p. 